\title{
A Simplified Ozone Model Based on Fuzzy Rules Generation
}

Mina Ryoke ${ }^{1}$

Yoshiteru Nakamori'

Chris Heyes $^{2}$

Marek Makowski ${ }^{2}$

Wolfgang Schöpp ${ }^{2}$

'Japan Advanced Institute of Science and Technology, Ishikawa, Japan ${ }^{2}$ International Institute for Applied Systems Analysis, Laxenburg, Austria

RR-00-07

March 2000

Reprinted from European Journal of Operational Research 122 (2000) 440-451. 
Research Reports, which record research conducted at IIASA, are independently reviewed before publication. Views or opinions expressed herein do not necessarily represent those of the Institute, its National Member Organizations, or other organizations supporting the work.

Reprinted from European Journal of Operational Research 122 (2000) 440-451.

Copyright (C) (2000), with permission from Elsevier Science.

All rights reserved. No part of this publication may be reproduced or transmitted in any form or by any means, electronic or mechanical, including photocopy, recording, or any information storage or retrieval system, without permission in writing from the copyright holder. 


\title{
A simplified ozone model based on fuzzy rules generation
}

\author{
Mina Ryoke ${ }^{\text {a }}$, Yoshiteru Nakamori ${ }^{\text {a }}$, Chris Heyes ${ }^{\text {b }}$, Marek Makowski ${ }^{\text {b,*, }}$ \\ Wolfgang Schöpp ${ }^{b}$ \\ a Japan Advanced Institute of Science and Technology: 1-1 Asahidai, Tatsunokuchi, Ishikawa 923-1292, Japan \\ b International Institute for Applied System Analysis, Schlossplatz 1, A-2361 Laxenburg, Austria
}

Received 1 October 1998; accepted 1 April 1999

\begin{abstract}
In this paper, simplified ozone models for potential use in integrated assessment are developed from the EMEP ozone model, which is a single-layer Lagrangian trajectory model. The simplification method uses fuzzy rule generation methodology to represent numerous results of the EMEP model as a response surface describing the source-receptor relationships between ozone precursor emissions and daily tropospheric ozone concentrations. (c) 2000 Elsevier Science B.V. All rights reserved.
\end{abstract}

Keywords: Modeling; Fuzzy sets; Environment; Tropospheric ozone

\section{Introduction}

Major concerns about the environmental impacts of air pollution exist in many parts of the world. In some cases, such concerns have led to the introduction of measures to reduce the emissions of air pollutants in order to limit their negative effects.

\footnotetext{
Corresponding author. Tel.: +43-2236-8070; fax: +43-223671-313.

E-mail addresses: ryoke@jaist.ac.jp (M. Ryoke), nakamori@jaist.ac.jp (Y.Nakamori), heyes@iiasa.ac.at (C. Heyes), marek@iiasa.ac.at (M. Makowski), schoepp@iiasa.ac.at (W. Schöpp).
}

Within Europe interest in ground-level ozone has intensified in recent years, with increasing experimental evidence that ozone can have adverse effects on crops, trees, materials and human health. Studies of the impacts of ozone have resulted in the establishment of critical levels for ozone in order to protect agricultural crops and forests, using a long-term exposure measure, the 'accumulated excess ozone' concept described by Fuhrer and Achermann (1994). A threshold concentration of $40 \mathrm{ppb}$ has been set for both crops and trees. This exposure index is referred to as AOT40, the accumulated exposure over a threshold of $40 \mathrm{ppb}$. In many parts of Europe the critical levels are exceeded and measures to reduce ozone concentrations in these areas will be needed to protect the relevant ecosystems. 
In line with the revised World Health Organisation (WHO) Air Quality Guidelines for Europe (see WHO, 1997), a maximum 8-hour average concentration of $60 \mathrm{ppb}$ has been proposed as the environmental objective relevant to the protection of human health. Because of current difficulties with the modeling of European abatement strategies for individual days over a multi-month period, which such an indicator implies, a surrogate AOT indicator (AOT60), analogous to AOT40 for vegetation, has been introduced. An AOT60 - i.e., the cumulative excess exposure above $60 \mathrm{ppb}$, for practical reasons over a six-month period - of zero is considered to be equivalent to the full achievement of the WHO criterion. Although the AOT60 has proved useful as a practical, surrogate indicator for risk to human health, an alternative method designed to handle shorter term, e.g., daily, ozone concentrations above $60 \mathrm{ppb}$ remains a desirable objective.

The timescale of ozone production is such that ozone concentrations build up in polluted air over several days under suitable weather conditions, and this pollutant and its precursors can be transported over considerable distances and across national boundaries. Consequently, measures to control ozone require international cooperation if they are to be successful and costeffective. During the last decade several international agreements have been reached in Europe to reduce emissions - of sulphur dioxide $\left(\mathrm{SO}_{2}\right)$, nitrogen oxides $\left(\mathrm{NO}_{x}\right)$ and volatile organic compounds (VOC) - in a harmonized way. The negotiations leading to the more recent agreements have benefited greatly from the assistance given by integrated assessment models, which bring together in a consistent framework information on emission generation, emission control technologies and abatement costs, the long-range transport of pollutants and the environmental sensitivities of different areas of Europe. In addition to assessing the environmental impacts of alternative strategies for emission reductions, integrated assessment models can also be used in an 'optimization' mode to identify those strategies that minimize the costs required to achieve a given set of environmental targets. Such models have now been developed further to take groundlevel ozone into account.

An essential requirement of an integrated assessment model for ozone is a simplified but reliable description of the ozone formation process in order to represent the source-receptor relationships involved. It is possible to envisage several ways of condensing the results of more complex models of ozone formation to achieve this. One approach is to use statistical techniques to summarize the results obtained from a complex mathematical model for a large number of emission reduction scenarios. Two examples of this approach based on the EMEP photochemical model have been described, one using local regression techniques (Heyes and Schöpp, 1995) to model daily ozone concentrations, the other involving linear regression models of seasonal mean values (Heyes et al., 1996). The optimization problem related to the second of these methods is outlined by Makowski (2000) and it is this method that has been incorporated recently into the RAINS integrated assessment model described by Schöpp et al. (1999).

The subject of this paper is an alternative method of representing the results of the EMEP model as a response surface using fuzzy rule generation methodology (Nakamori and Ryoke, 1994). The idea is to construct a number of fuzzy rules about the source-receptor relationships between ozone precursor emissions and daily tropospheric ozone concentrations. Actual ozone concentrations also depend on many local factors such as topographical location, local emissions and meteorological conditions. Taking account of such factors requires at least a daily model such as that provided by this approach. If developed for a sufficient number of receptor points, the set of fuzzy rules could be used as an alternative simplified ozone model.

Section 2 of the paper provides an outline of the salient features of ozone formation photochemistry, a brief description of the EMEP photochemical model and an explanation of the variables used in building the fuzzy model. As an example of the method, a fuzzy model developed for a receptor grid located in Austria is presented in Section 3. 


\section{Background}

\subsection{Ozone formation}

The formation of ozone involves chemical reactions between $\mathrm{NO}_{x}$ (i.e., nitric oxide (NO) and nitrogen dioxide $\left(\mathrm{NO}_{2}\right)$ taken together) and VOCs driven by solar radiation, and occurs on a regional scale in many parts of the world. A complete description of the processes involved is beyond the scope of this paper; the following very brief outline serves only to highlight some of the important relevant features.

Ozone production requires the combination of atomic and molecular oxygen. In the troposphere, photodissociation of $\mathrm{NO}_{2}$ is the only significant source of oxygen atoms. The ozone produced as a result of this photodissociation may then react with $\mathrm{NO}$ to regenerate $\mathrm{NO}_{2}$, leading to the establishment of a photochemical steady state between $\mathrm{O}_{3}$, $\mathrm{NO}$ and $\mathrm{NO}_{2}$ in a relatively unpolluted atmosphere during hours with sunlight.

The photochemical steady state will be perturbed by any processes, other than reaction with $\mathrm{O}_{3}$, which convert $\mathrm{NO}$ to $\mathrm{NO}_{2}$, such processes resulting in the net production of ozone. This is made possible when VOCs are also present in the atmosphere. The essential first step in a potentially complex chain of reactions involving VOCs is attack by hydroxyl radicals $(\mathrm{OH})$. Subsequent reactions can form peroxy and hydroperoxy radical species which are able to oxidize $\mathrm{NO}$ to $\mathrm{NO}_{2}$, and therefore lead to enhanced ozone formation. Thus, $\mathrm{NO}_{x}$ and VOC species and the presence of sunlight are all necessary prerequisites for the production of ozone within the atmospheric boundary layer.

One of the main processes which removes free radicals, and therefore opposes ozone formation, is the combination of $\mathrm{OH}$ radicals with $\mathrm{NO}_{2}$. When $\mathrm{NO}_{2}$ concentrations are very high, as they may be in areas of high $\mathrm{NO}_{x}$ emission density, the $\mathrm{NO}_{2}$ competes with VOCs for reaction with $\mathrm{OH}$, and inhibits the production of ozone. Consequently, $\mathrm{NO}_{x}$ exerts a nonlinear influence on tropospheric ozone formation. This feature of ozone photochemistry has important implications for emission control strategies designed to reduce ozone concentrations.
While emissions of ozone precursors are clearly essential for ozone formation, meteorological factors also exert a crucial influence. The intensity of the incoming solar radiation must be high, and temperature is also important in influencing the rates of many of the chemical reactions involved. Other conditions favorable to ozone formation are low windspeeds and a persistent, well-defined atmospheric boundary layer. Other important factors in determining ozone concentrations at ground level are the rate at which ozone is removed by deposition to terrestrial surfaces and mixing processes occurring in the troposphere.

\subsection{The EMEP ozone model}

Within the UNECE European Monitoring and Evaluation Programme (EMEP) a Europe-wide ozone model has been developed at the Meteorological Synthesizing Centre-West in Oslo. This EMEP ozone model has been designed with the purpose of simulating ozone formation over long periods of time (one month to one year) and over the whole of Europe, so that the likely effects of emission control measures on long-term ozone concentrations can be estimated.

The EMEP ozone model (Simpson, 1992, 1993, 1995) is a single-layer Lagrangian trajectory model with a variable depth which extends from the ground to the top of the atmospheric boundary layer. The model calculates concentrations of photochemical oxidants every 6 hours for a set of up to 740 arrival points (on a $150 \mathrm{~km} \times 150 \mathrm{~km}$ grid) covering the whole of Europe. Columns of air in the atmospheric boundary layer are followed along specified 96-hour trajectories, picking up emissions of $\mathrm{NO}_{x}, \mathrm{VOC}, \mathrm{CO}$ and $\mathrm{SO}_{2}$ from the underlying grid. The height of the air column, the mixing height, containing the bulk of the polluted air is reset at 12 GMT each day from radiosonde data. Along each trajectory the mass conservation equations are integrated, taking into account emission inputs, photolysis and chemical reactions, dry and wet removal, and the influence of meteorological parameters. These equations are solved numerically, currently using 
the quasi-steady state approximation method with a fixed time step of 15 minutes.

The six-hourly meteorological data required by the EMEP model are taken from the output of the Norwegian Numerical Weather Prediction model. Wind velocity data permit calculation of 96-hour back-trajectories to any point in the EMEP grid. The ozone model simulates the exchange of boundary layer air with free tropospheric air as a result of convective clouds. Photolysis rates are adjusted for cloud cover, and temperature data are used to calculate appropriate chemical reaction rates and in estimating natural VOC emissions. Other meteorological data are used in estimating deposition velocities, which are calculated as a function of atmospheric stability, latitude, time of year and time of day.

The anthropogenic emissions of $\mathrm{NO}_{x}, \mathrm{VOC}$, $\mathrm{CO}$ and $\mathrm{SO}_{2}$ used in the model are based, as far as possible, on data supplied officially at a national level. For use in the ozone model, the emissions data are spatially disaggregated onto a $50 \mathrm{~km} \times$ $50 \mathrm{~km}$ grid. Natural emissions of VOCs are represented in the EMEP ozone model by the emissions of isoprene from forests and agricultural crops (see Simpson, 1995). These are calculated at each time step using surface temperature data, land-use data for each grid square and published emission-temperature relationships.
The EMEP model uses a chemical mechanism in which each important VOC class is represented by one or two members whose chemical degradation is followed explicitly. The chemical mechanism comprises 136 reactions, including 25 photolysis reactions, and the model calculates explicitly the concentrations of 61 chemical species. Methane is treated in the model as a tropospheric background species. Initial concentrations of all species at the start of each 96-hour trajectory are taken from previous model calculations, if available; otherwise a set of assumed background tropospheric concentrations, based on appropriate measured data or tropospheric model calculations, is used.

\subsection{Generation of input data}

Input data for the fuzzy model are generated from EMEP model calculations carried out using 1990 emissions data and meteorological data for the period April-September 1990. The countries and regions contributing data of annual emissions of $\mathrm{NO}_{x}$ and VOC are shown in Table 1.

Two main scenarios are calculated: first is the 1990 'base' case with unabated emissions, second a scenario involving uniform emission reductions

Table 1

Emitter regions in the EMEP model

\begin{tabular}{|c|c|c|c|c|c|}
\hline 1 & Albania & 2 & Austria & 3 & Belgium \\
\hline 4 & Bulgaria & 6 & Denmark & 7 & Finland \\
\hline 8 & France & 9 & East Germany & 10 & Germany \\
\hline 11 & Greece & 12 & Hungary & 13 & Iceland \\
\hline 14 & Ireland & 15 & Italy & 16 & Luxembourg \\
\hline 17 & Netherlands & 18 & Norway & 19 & Poland \\
\hline 20 & Portugal & 21 & Rumania & 22 & Spain \\
\hline 23 & Sweden & 24 & Switzerland & 25 & Turkey \\
\hline 27 & United Kingdom & 29 & Other land areas & 30 & Baltic Sea \\
\hline 31 & North Sea & 32 & Remaining NE Atlantic & 33 & Mediterranean \\
\hline 35 & Nat ocean emissions & 36 & Kola/Karelia & 37 & St. Peter/Novgo Pskov \\
\hline 38 & Kaliningrad & 39 & Belarus & 40 & Ukraine \\
\hline 41 & Moldova & 42 & Rest of the Russian Fed. & 43 & Estonia \\
\hline 44 & Latvia & 45 & Lithuania & 46 & Czech Republic \\
\hline 47 & Slovakia & 48 & Slovenia & 49 & Croatia \\
\hline 50 & Bosnia Herzegovina & 51 & Serbia, Montenegro & 52 & Macedonia \\
\hline 53 & Kazakhstan & 54 & Georgia & & \\
\hline
\end{tabular}


across all European countries. In this second scenario, emissions of $\mathrm{NO}_{x}$, VOC and $\mathrm{CO}$ are reduced, from all man-made emission sources, by $70 \%$. In addition to these two main scenarios, numerous 'individual country' scenarios, in which emissions of a single pollutant from a single emitter country are reduced, are also investigated. The results from these model runs provide information on the influence of precursor emissions from individual countries on the results at a given receptor grid. Although there are many possible combinations for reducing precursor emissions, we have limited our study to the scenarios summarized in Table 2.

For this exercise, results from the EMEP model are obtained for three receptor grids, one in NW England, one in SW Germany and one covering the Upper Austria region of Austria. Results from this third grid, which includes the industrial towns of Linz and Wels as well as some remote areas such as the Salzkammergut, are presented by Ryoke (1996). In each of these three regions some nonlinear behavior with $\mathrm{NO}_{x}$ emissions is to be expected. The EMEP results provided data on ozone concentrations, photolysis rates of $\mathrm{NO}_{2}$ and a dilution-weighted or 'effective' integrated emissions parameter which allows for losses of emitted species along an air mass trajectory.

In the EMEP ozone model, the emissions and meteorological input data are revised at 2-hour intervals, so that there are 49 time steps during

Table 2

Outline of scenario emission factors

\begin{tabular}{lcclll}
\hline & \multicolumn{2}{l}{$\begin{array}{l}\text { Individual } \\
\text { countries }\end{array}$} & & \multicolumn{2}{l}{$\begin{array}{l}\text { All (other) } \\
\text { countries }\end{array}$} \\
\cline { 2 - 3 } \cline { 5 - 6 } & $\mathrm{NO}_{x}$ & $\mathrm{VOC}$ & & $\mathrm{NO}_{x}$ & $\mathrm{VOC}$ \\
\hline Base Scenario1 & - & - & & 1.0 & 1.0 \\
Base Scenario2 & - & - & & 0.3 & 0.3 \\
Scenario1 & 1.0 & 0.6 & & 1.0 & 1.0 \\
Scenario2 & 0.8 & 1.0 & & 1.0 & 1.0 \\
Scenario3 & 0.6 & 1.0 & & 1.0 & 1.0 \\
Scenario4 & 0.3 & 0.7 & & 0.3 & 0.3 \\
Scenario5 & 0.5 & 0.3 & & 0.3 & 0.3 \\
Scenario6 & 0.7 & 0.3 & & 0.3 & 0.3 \\
\hline
\end{tabular}

the four-day trajectory. Two processes are included in the model which lead to mixing of the boundary layer air parcels with free tropospheric air: the venting effect of cumulus clouds and dayto-day increases in mixing height. These exchange mechanisms operate at 2 -hour intervals. If the emissions of an ozone precursor during time step $i$ are denoted by $E_{i}$, and the exchange processes result in a dilution of the boundary layer air by a dilution factor $d_{i}\left(0<d_{i} \leqslant 1\right)$, the contribution from time step $i$ to the trajectory-integrated value of the precursor emissions, $E$, at time step $(i+1)$ is given simply by

$$
E_{i} \times d_{i+1} .
$$

The integrated contribution from all 49 time steps, denoted by $\langle E\rangle$, is given by

$\langle E\rangle=\sum_{i=1}^{i=48}\left(E_{i} \times \prod_{j=i+1}^{j=49} d_{j}\right)+E_{49}$.

Such quantities are calculated for both $\mathrm{NO}_{x}$ and VOC emissions along each trajectory and investigated as predictor variables in regression models of the fuzzy model.

The following variables are considered in the fuzzy modeling approach:

- Ozone concentration (ppb): The dependent variable is taken as the daily $\mathrm{O}_{3}$ concentration calculated for the 12 GMT trajectory arrival. This value is assumed to represent the early afternoon concentration when $\mathrm{O}_{3}$ is expected to be at or near its daily maximum value.

- Contributions to effective $N O_{x}\left(10^{10}\right.$ molecules $\mathrm{cm}^{-2}$ ): From the results of the individual country scenarios it is possible to calculate the contributions from individual emitter countries to effective emissions at a particular receptor grid. These data constitute weighted meteorological information. The individual country contributions to effective $\mathrm{NO}_{x}$ from the six most influential (usually neighboring) countries for the selected grid are used in the fuzzy modeling exercise. These combine information about the path taken by the air mass together with its atmospheric stability. 
- Contributions to effective VOC $\left(10^{10}\right.$ molecules $\mathrm{cm}^{-2}$ ): These data are the VOC analogue of the effective $\mathrm{NO}_{x}$ contributions above; they are not used as the information they provide is similar to that from the effective $\mathrm{NO}_{x}$ contributions.

- Effective $N O_{x}\left(10^{10}\right.$ molecules $\left.\mathrm{cm}^{-2}\right)$ : The daily 12 GMT effective $\mathrm{NO}_{x}$ values at the selected grid, which include the contributions from all European countries and non-controllable sources, are used. This variable represents the total $\mathrm{NO}_{x}$ potentially available for reaction during the course of the four-day trajectory. At the arrival point some of this $\mathrm{NO}_{x}$ will have been lost through chemical reaction but is 'remembered' in the form of ozone or other species produced.

- Effective VOC $\left(10^{10}\right.$ molecules $\left.\mathrm{cm}^{-2}\right)$ : These data are again the VOC analogue of the effective $\mathrm{NO}_{x}$ values and include both man-made emissions from all the countries and natural VOC emissions.

- $\mathrm{NO}_{2}$ photolysis rate $\left(10^{-3} \mathrm{~s}^{-1}\right)$ : The value used is the mean photolysis rate over the final 30 hours of the trajectory. This is used to represent solar radiation, which affects ozone formation, and is dependent on the cloud cover.

- Mixing factor $(0<$ mixing factor $\leqslant 1)$ : The mixing factor describes the extent of mixing between the boundary layer and the troposphere. A value of 0 would indicate complete mixing, 1 no mixing.

The combination of individual country contributions to effective $\mathrm{NO}_{x}$ and the photolysis rate of $\mathrm{NO}_{2}$ provides information about the meteorological conditions experienced by an air mass during the course of its travel to the selected receptor grid. It may be helpful, in some circumstances, to aggregate the contributions made by some countries when their patterns of influence are similar.

\subsection{Implementation}

We have developed a fuzzy modeling technique and corresponding modeling software with a highly interactive graphical user interface using the $\mathrm{C}$-language and the $\mathrm{Tcl} / \mathrm{Tk}$ toolkit. The objective function consists of two parts related to the re- gression errors and the data distances, respectively. Two dynamically changing parameters are introduced to make a balance of the above-mentioned two objectives. The software supports examination of the clustering results (for any two selected clustering variables), of the regression results with statistics for judging goodness of linear models, and simulation results by the developed fuzzy model.

\section{Fuzzy model at a grid in Upper Austria}

A previous pilot study presented by Ryoke (1996) showed that the fuzzy model provides a useful way to summarize results of the EMEP ozone model. It was found that the concept of effective precursor emissions is sufficient to model adequately the daily variation of ozone. However, the previous study was based on uniform emission control across Europe. The present study extends the work to include emission reduction scenarios for individual European countries.

\subsection{Data and scenarios screening}

The time period covers six months: AprilSeptember 1990. Daily values are provided, referring to 12 GMT air mass trajectory arrivals.

For each grid there are data for two 'base' cases involving the full set of countries considered. In such a scenario all countries make the same fractional changes to both their $\mathrm{NO}_{x}$ and VOC emissions. For these 'base' cases ozone concentration data are provided for all those days on which the following two conditions hold:

1. the solar radiation is considered high enough for reasonable ozone production to occur,

2. there is not so much mixing with the free troposphere that man-made emissions can have only very little influence on ozone concentrations.

In addition to the two base cases, there are six further country-specific scenarios for each of the six influential emitter countries, making a total of $38(=2+6 \times 6)$ scenarios for each receptor grid. 
The combinations of emission reductions employed for these country-specific scenarios are outlined in Table 2.

Data for these additional 36 scenarios are provided for days:

1. which meet the criteria given above for the 'base' cases (enough solar radiation and not too much mixing) and

2. for which the 'scenario' ozone concentration does actually differ from the appropriate 'base case' value.

That is, data are excluded for those days on which an emission change in one country has no effect on ozone concentration at the particular grid in question.

\subsection{Fuzzy model}

The model at the receptor $j$ consists of $c_{j}$ fuzzy rules. Let $p v_{j 1}$ be the effective $\mathrm{NO}_{x}$ from all countries to the grid calculated by the EMEP ozone model with scenarios. If $p v_{j 1}$ is very high, the concentrations of radicals which are necessary for ozone production will be distorted. Let $p v_{j 2}$ be the effective $\mathrm{NO}_{x}$ from countries excluding the country in which the grid $j$ is located and calculated with the emissions of scenario 'Base Scenariol' in Table 2. If $p v_{j 2}$ is high, there is a larger long-range transport component. Let $p v_{j 3}$ be a mixing factor. If $p v_{j 3}$ is low, considerable mixing of free tropospheric air into the boundary layer takes place. Ozone concentration will very much depend on the free tropospheric ozone value. If $p v_{j 3}$ is high the boundary layer production is an important component for ozone. Let $p v_{j 4}$ be the photolysis rate of $\mathrm{NO}_{2}$. When $p v_{j 4}$ is high, we have a lot of sunshine and a large ozone production capacity.

Rule $R_{j}^{p}$ is given as follows:

$$
\begin{aligned}
& \text { If }\left(p v_{j 1}, p v_{j 2}, p v_{j 3}, p v_{j 4}\right) \text { is } A_{j}^{p} \text { (a fuzzy subset), } \\
& \text { then } o z_{j}^{p}=k_{j}^{p}+\sum_{i \in I_{j}} \alpha_{i j}^{p} n_{i}+\sum_{i \in I_{j}} \beta_{i j}^{p} v_{i}
\end{aligned}
$$

where $i \in I$ denotes emitters (countries), $j \in J$ the receptors (grids), $I_{j}$ the highly influencing emitters to the receptor $j, n_{i}$ the emission of $\mathrm{NO}_{x}$ from the emitter $i, v_{i}$ the emission of VOCs from the emitter $i$, and $o z_{j}$ is ozone concentration at the receptor $j$.

In the consequence part, the relation between consequence variables is independent of time $t$ and scenario $s$ explicitly. They are already given by the EMEP ozone model which considers trajectories for 96 hours. Actually, they are related to premise variables implicitly.

$A_{j}^{p}$ is a fuzzy subset in the four-dimensional space spanned by $p v_{j 1}, p v_{j 2}, p v_{j 3}$, and $p v_{j 4}$. Let $f_{j}^{p}(\boldsymbol{x})$ be the membership grade in $A_{j}^{p}$, used to calculate the degree of confidence of a rule, which is a nonlinear function and $0 \leqslant f_{j}^{p}(\boldsymbol{x}) \leqslant 1$. The degree of confidence of rules $f_{j}^{p}(\boldsymbol{x})$ is defined as follows. First of all, the membership function of a premise variable $x_{k}$ is defined by using the subset $Z_{j k}^{p}$ which corresponds to the data set to build Rule $R_{j}^{p}$.

$$
\begin{aligned}
& \mu_{j k}^{p}\left(x_{k} ; q_{k 1}^{p}, q_{k 2}^{p}, q_{k 3}^{p}, t_{k 1}^{p}, t_{k 2}^{p}\right) \\
& \quad= \begin{cases}\exp \left\{-\frac{\left(x_{k}-q_{k 2}^{p}\right)^{2}}{2\left(t_{k 1}^{p}\right)^{2}\left(q_{k 1}^{p}-q_{k 2}^{p}\right)^{2}}\right\}, & x_{k} \leqslant q_{k 2}^{p}, \\
\exp \left\{-\frac{\left(x_{k}-q_{k 2}^{p}\right)^{2}}{2\left(t_{k 2}^{p}\right)^{2}\left(q_{k 3}^{p}-q_{k 2}^{p}\right)^{2}}\right\}, & x_{k} \geqslant q_{k 2}^{p},\end{cases}
\end{aligned}
$$

where the first, second and third quartiles of the data subset $p$ are denoted by $q_{k 1}^{p}, q_{k 2}^{p}$ and $q_{k 3}^{p}$, respectively. The second quartile corresponds to the medium of data distribution on the axis. The first and third quartiles are defined so that the first one is smaller than the third one. If two of them are equal, give one of them a small fluctuation to keep the restriction that $q_{k 1}^{p}<q_{k 2}^{p}<q_{k 3}^{p}$. The tuning parameters $t_{k 1}^{p}, t_{k 2}^{p}$ have default 1 and they are optimized in the identification of the fuzzy model (see Nakamori and Ryoke, 1994). Next, the membership function for Rule $R_{j}^{p}$ is defined by

$f_{j}^{p}(\boldsymbol{x})=\prod_{k=1}^{4} \mu_{j k}^{p}\left(x_{k} ; q_{k 1}^{p}, q_{k 2}^{p}, q_{k 3}^{p} ; t_{k 1}^{p}, t_{k 2}^{p}\right)$.

Estimation of $o z_{j}$ is done by the following formula: For a given $\boldsymbol{x}=\left(p v_{j 1}, p v_{j 2}, p v_{j 3}, p v_{j 4}\right)$,

$\hat{o z}_{j}=\frac{\sum_{p=1}^{c_{j}} f_{j}^{p}(\boldsymbol{x}) \cdot o z_{j}^{p}}{\sum_{p=1}^{c_{j}} f_{j}^{p}(\boldsymbol{x})}$. 
Table 3

A regression model at a receptor located in Upper Austria

\begin{tabular}{|c|c|c|}
\hline \\
\hline \multicolumn{3}{|l|}{$\begin{aligned} \text { Ozone }= & 41.760 \\
& +1632 . \times \mathrm{NO}_{x} \text { from Austria }\end{aligned}$} \\
\hline$+646.2 \times \mathrm{NO}_{x}$ from France & $($ tratio $=+1.41)$ & $($ correl. $=+0.08)$ \\
\hline$+537.8 \times \mathrm{NO}_{x}$ from East Germany & $($ tratio $=+1.78)$ & $($ correl. $=+0.25)$ \\
\hline$+119.2 \times \mathrm{NO}_{x}$ from West Germany & $($ tratio $=+0.99)$ & $($ correl.$=+0.24)$ \\
\hline$+346.5 \times \mathrm{NO}_{x}$ from Italy & $($ tratio $=+1.70)$ & $($ correl.$=+0.32)$ \\
\hline$+304.1 \times \mathrm{NO}_{x}$ from Czech Rep. & $($ tratio $=+1.27)$ & $($ correl.$=+0.20)$ \\
\hline +910.6 × VOC from Austria & $($ tratio $=+3.64)$ & $($ correl.$=+0.53)$ \\
\hline$+621.2 \times$ VOC from France & $($ tratio $=+1.36)$ & $($ correl.$=+0.08)$ \\
\hline$+861.0 \times$ VOC from East Germany & $($ tratio $=+2.87)$ & $($ correl.$=+0.25)$ \\
\hline$+349.2 \times$ VOC from West Germany & $(t$ ratio $=+1.93)$ & $($ correl.$=+0.24)$ \\
\hline$+548.6 \times$ VOC from Italy & $($ tratio $=+2.71)$ & $($ correl.$=+0.32)$ \\
\hline$+25.19 \times$ VOC from Czech Rep. & $($ tratio $=+0.11)$ & $($ correl.$=+0.20)$ \\
\hline
\end{tabular}

$\left(R^{2}\right)^{*}=0.4590, \quad T(2383,0.05)=1.961$.

\subsection{Model parameters and prediction result}

Before going into fuzzy modeling, a regression model is developed by using all data. A regression model is determined by the least square method and shown in Table 3.

Here, $\left(R^{2}\right)^{*}$ denotes the coefficient of determination adjusted for the degree of freedom and $T(2383,0.05)$ is the 5 percentile of the

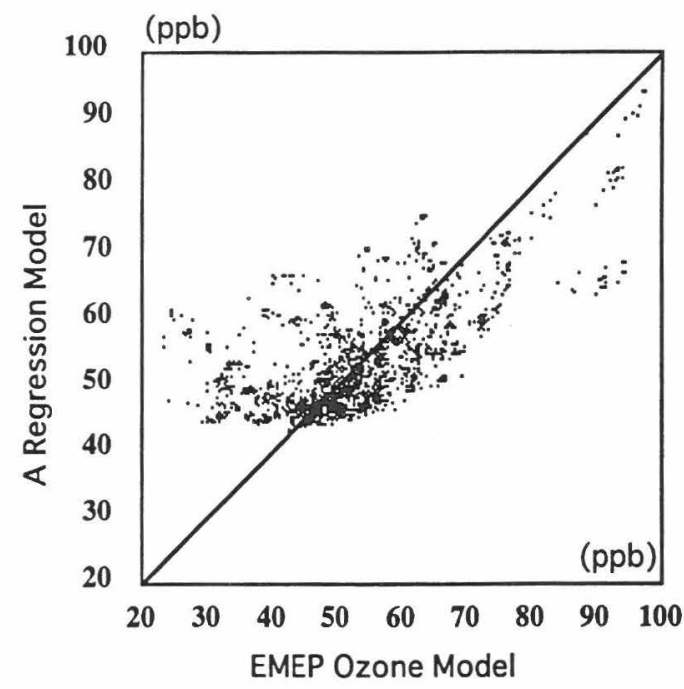

Fig. 1. Prediction result by a regression model. $t$-distribution with the degrees of freedom 2383 . In the equation, the tratio of the regression coefficients and the correlation coefficients of explanatory variables with ozone are also shown. The correlation coefficient between predictions by EMEP ozone model and the traditional regression model is 0.6708 . In Fig. 1, the prediction result by the linear regression model is shown.

Table 4

Clustering variables

\begin{tabular}{ll}
\hline Response variable & Ozone concentrations \\
\hline Premise variables & $p v_{1}$ \\
& $p v_{2}$ \\
& $p v_{3}$ \\
& $p v_{4}$ \\
& $\mathrm{NO}$ from Austria \\
Consequence variables & $\mathrm{NO}$ from France \\
& $\mathrm{NO}$ from East Germany \\
& $\mathrm{NO}$ from West Germany \\
& $\mathrm{NO}$ from Italy \\
& $\mathrm{NO}$ from Czech Rep. \\
& VOC from Austria \\
& VOC from France \\
& VOC from East Germany \\
& VOC from West Germany \\
& VOC from Italy \\
& VOC from Czech Rep. \\
\end{tabular}


Table 5

Parameters of premise variables in Rule 1

\begin{tabular}{llllllll}
\hline Premise variables & $\min$. & $q_{1}$ & $q_{2}$ & $q_{3}$ & $\max$. & $\boldsymbol{t}_{1}$ & $\boldsymbol{t}_{2}$ \\
\hline$p v_{1}$ & 0.001917 & 0.004180 & 0.007426 & 0.01059 & 0.02363 & 3.4 & 4.1 \\
$p v_{2}$ & 0.004594 & 0.01210 & 0.01623 & 0.02287 & 0.04126 & 1.0 & 4.7 \\
$p v_{3}$ & 0.4008 & 0.4527 & 0.5102 & 0.5568 & 0.7498 & 4.6 & 3.4 \\
$p v_{4}$ & 2.178 & 2.400 & 2.844 & 3.179 & 3.484 & 2.0 & 1.2 \\
\hline
\end{tabular}

Table 6

Consequence coefficients in Rule 1

\begin{tabular}{lc}
\hline Consequence variables & Coefficient \\
\hline $\mathrm{NO}_{x}$ from Austria & 1512 \\
$\mathrm{NO}_{x}$ from France & -1889 \\
$\mathrm{NO}_{x}$ from East Germany & -111.9 \\
$\mathrm{NO}_{x}$ from West Germany & -287.8 \\
$\mathrm{NO}_{x}$ from Italy & 186.8 \\
$\mathrm{NO}_{x}$ from Czech Rep. & 18.55 \\
Constant & 38.95 \\
VOC from Austria & 1534 \\
VOC from France & 993.8 \\
VOC from East Germany & 598.76 \\
VOC from West Germany & 360.1 \\
VOC from Italy & 706.9 \\
VOC from Czech Rep. & -73.61 \\
\hline
\end{tabular}

Now, we briefly summarize fuzzy models developed for one grid in Europe. First step of fuzzy modeling for the selected grid is provided by the adaptive fuzzy clustering presented by Ryoke et al. (1998) in order to obtain the classification and regressions in each rule. According to the above discussion, the clustering variables are given as in Table 4. Note, that the consequence variables $\mathrm{NO}_{x}$ and VOC specified in Tables 4, 6, 8 and 10 stand for the corresponding country contributions to effective $\mathrm{NO}_{x}$ and to effective VOC, respectively.
The reason why the adaptive fuzzy clustering proposed in Ryoke et al. (1998) is used, is that these clustering variables are highly correlated with each other. The number of clusters, determined by a trial and error approach, has been set to 3 . In the next step, the tuning parameters of the premise variables have been optimized. The modeling system (outlined in Section 2.4) has been developed so that the modelers can carry out the fuzzy modeling interactively. The above clustering method and the tuning method for the premise parameters are also included in the system with graphical user interface.

The values of parameters in the developed fuzzy model are shown in Tables 5-10. The membership functions of the premise variables are illustrated in Figs. 2-5. The vertical axis means the grade of the membership function for each rule. The prediction result is presented in Fig. 6 . The correlation coefficient between predictions by the obtained fuzzy model and the EMEP ozone model is 0.811 .

\section{Concluding remarks}

This paper presents fuzzy models expressing relationships between precursor emissions of $\mathrm{NO}_{x}$

Table 7

Parameters of premise variables in Rule 2

\begin{tabular}{llllllll}
\hline Premise variables & min. & $q_{1}$ & $q_{2}$ & $q_{3}$ & $\max$. & $t_{1}$ & $t_{2}$ \\
\hline$p v_{1}$ & 0.001844 & 0.005340 & 0.007384 & 0.01185 & 0.02463 & 4.6 & 3.6 \\
$p v_{2}$ & 0.006268 & 0.01456 & 0.02013 & 0.02577 & 0.03717 & 4.0 & 2.3 \\
$p v_{3}$ & 0.4097 & 0.4613 & 0.5148 & 0.6063 & 0.9701 & 4.8 & 3.9 \\
$p v_{4}$ & 3.177 & 3.7462 & 4.1964 & 4.4047 & 4.644 & 0.7 & 3.7 \\
\hline
\end{tabular}


Table 9

Parameters of premise variables in Rule 3

\begin{tabular}{llllllll}
\hline Premise variables & $\min$. & $q_{1}$ & $q_{2}$ & $q_{3}$ & $\max$ & $t_{1}$ & $t_{2}$ \\
\hline$p u_{1}$ & 0.004659 & 0.01254 & 0.01972 & 0.02415 & 0.05591 & 2.0 & 2.3 \\
$p v_{2}$ & 0.01283 & 0.02851 & 0.03576 & 0.04547 & 0.08769 & 0.8 & 1.6 \\
$p u_{3}$ & 0.4207 & 0.6025 & 0.691 & 0.7820 & 0.9701 & 2.0 & 4.2 \\
$p u_{4}$ & 2.288 & 3.635 & 4.130 & 4.402 & 4.644 & 4.2 & 2.2 \\
\hline
\end{tabular}

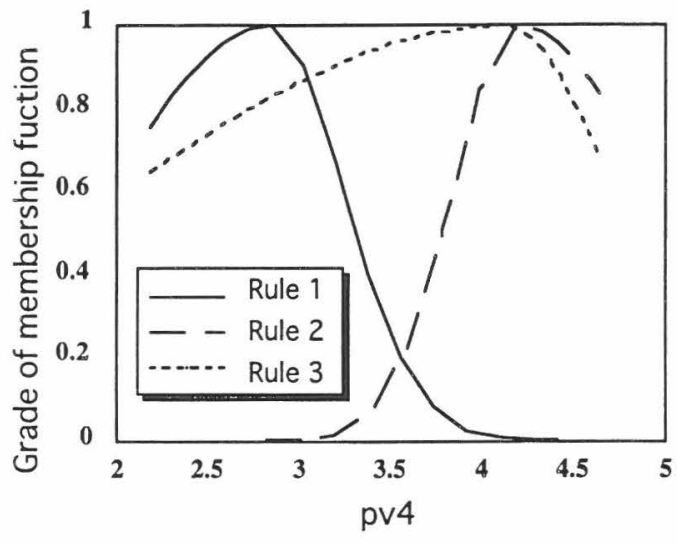

Fig. 5. Membership function of $p v_{4}$.

Table 10

Consequence coefficients in Rule 3

\begin{tabular}{lc}
\hline Consequence variables & Coefficient \\
\hline NO, from Austria & 1403 \\
NO, from France & 911.1 \\
NO, from East Germany & 598.3 \\
NO, from West Germany & 169.5 \\
NO, from Italy & 401.1 \\
NO, from Czech Rep. & 226.7 \\
Constant & 41.97 \\
VOC from Austria & 795.3 \\
VOC from France & 1013 \\
VOC from East Germany & 1028 \\
VOC from West Germany & 392.3 \\
VOC from Italy & 630.2 \\
VOC from Czech Rep. & 253.4 \\
\hline
\end{tabular}

After developing fuzzy models in principal grids, interpolation is needed to predict the ozone concentrations in other grids in central and western Europe. One of the methods considered is to define a similarity measure between receptors.

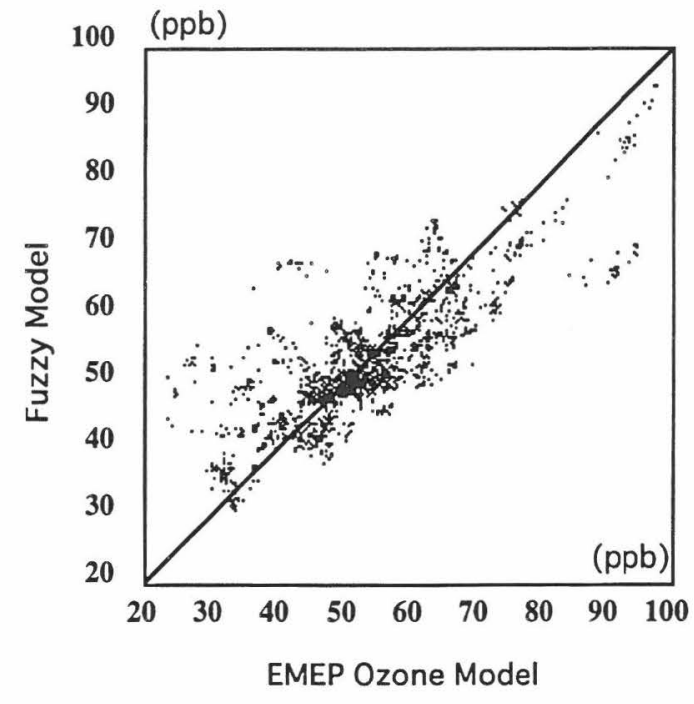

Fig. 6. Prediction result by the fuzzy model.

\section{References}

Fuhrer, J., Achermann, B., 1994. Critical levels for ozone. UN-ECE Workshop Report. FAC No. 16. Swiss Federal Research Station for Agricultural Chemistry and Environmental Hygiene, Switzerland.

Heyes, C., Schöpp, W., 1995. Towards a simplified model to describe ozone formation in Europe. Working Paper WP95-34. International Institute for Applied Systems Analysis (IIASA), Laxenburg, Austria.

Heyes, C., Schöpp, W., Amann, M., 1996. A simplified model to predict long-term ozone concentrations in Europe. Working Paper WP-96-12. International Institute for Applied Systems Analysis (IIASA), Laxenburg, Austria

Makowski, M., 2000. Modeling paradigms applied to the analysis of European air quality. European Journal of Operational Research 122, this issue.

Nakamori, Y., Ryoke, M., 1994. Identification of fuzzy prediction models through hyperellipsoidal clustering. IEEE Transactions on Systems, Man and Cybernetics 24 (8), 1153-1173. 
Ryoke, M., 1996. Fuzzy rule generation from the EMEP ozone model to examine source receptor relations. Working Paper WP-96-130. International Institute for Applied Systems Analysis (IIASA), A-2361 Laxenburg, Austria.

Ryoke, M., Nakamori, Y., Tamura, H., 1998. Dynamic determination of mixing parameters in fuzzy clustering. In: Proceedings of the Sixth Conference of the International Federation of Classification Societies (IFCS-98), Rome, pp. 111-116.

Schöpp, W., Amann, M., Cofala, J., Heyes, C., Klimont, Z., 1999. Integrated assessment of European air pollution emission control strategies. Environmental Modelling \& Software 14, 1-9.
Simpson, D., 1992. Long-period modelling of photochemical oxidants in Europe, model calculations for july 1985. Atmospheric Environment 26A, 1609-1634.

Simpson, D., 1993. Photochemical model calculations over Europe for two extended summer periods: 1985 and 1989, model results and comparisons with observations. Atmospheric Environment 27A, 921-943.

Simpson, D., 1995. Biogenic emissions in Europe, 2, implications for ozone control strategies. Journal of Geophysical Research, 100.

WHO, 1997. Air Quality Guidelines for Europe, Second ed. WHO, Copenhagen. 
